EXEMPLARIa Classica

Journal of Classical Philology

17, 2013, pp. 245-278

ISSN 1699-3225

\title{
LOS LUGENTES CAMPI DE VIRGILIO (AEN. 6.439) EN DOS SONETOS DE LUIGI TANSILLO Y BERARDINO ROTA
}

\author{
Bienvenido Morros Mestres \\ Universidad Autónoma de Barcelona \\ bienvenido.morros@uab.cat
}

\section{SUMMARY}

This paper studies the two poets Italian sonnets composed about Queen Dido and painter Irene Spelimbergo. Luigi Tansilo devoted his to the Queen of Carthage, who stands at the "lugentes campi" very promptly following an episode of Virgil's Aeneid (the editors did not realize that debt and believed the Italian poet meant a lady wanted dead return to die out of jealousy). Berardino Rota devoted his sonnet to the painter Irene, who imagines the Champs Elysees and descending from them to the earth (made into an arch Iris because as a painter also planting colorful sky) to bring a message of peace. In his sonnet, Rota also refers to his dead wife (in the same year as Irene), of whom he says, to prove his love, to be sweeping the "lugentes campi" (he uses the singular).

KEYWORDS

Latin poetry and Italian Renaissance poetry, mythology, love and death, Dido and Irene Spilimbergo
RESUMEN

El presente trabajo estudia los sonetos que dos poetas italianos compusieron sobre la reina Dido y la pintora Irene de Spelimbergo. Luigi Tansilo dedicó el suyo a la reina de Cartago, a quien sitúa en los "lugentes campi", siguiendo muy puntualmente un episodio de la Eneida de Virgilio (los editores no se percataron de esa deuda y creyeron que el poeta italiano se refería una dama muerta que deseaba volver a morir por celos). Berardino Rota consagró su soneto a la pintora Irene, a quien imagina en los Campos Elíseos y descendiendo desde ellos a la tierra (convertida en una especie de arco Iris porque como pintora también siembra el cielo de colores) para llevar un mensaje de paz. En su soneto, Rota alude también a su esposa muerta (en el mismo año que Irene), por quien dice, en prueba de su amor, estar recorriendo los "lugentes campi" (él usa el singular).

Palabras Clave

poesía latina e italiana del Renacimiento, mitología, amor y muerte, Dido e Irene Spilimbergo

Fecha de recepción: 18/02/2013

Fecha de aceptación y versión final: 19/07/2013 


\section{Para Irene}

Los poetas que frecuentaban el Porticus Antonianus (después llamada Academia Pontaniana) en la segunda mitad del siglo XV descubrieron en los versos de Virgilio una perfección poética que no sólo intentaron imitar en sus obras sino que la reivindicaron en sus diálogos sobre teoría literaria: pretendían justificar las palabras que con sus sílabas habían de combinar en el verso en virtud de la materia que habían de tratar en él (buscaban en definitiva una especial y secreta sonoridad, que tanto admiraron en Virgilio, que representara la res no sólo fónica, con el uso de los sonidos adecuados, sino también visualmente) ${ }^{1}$. El primer autor que estudió semejante artificio sistemáticamente en la poesía de Virgilio (y especialmente en la Eneida) fue Giovanni Pontano en un diálogo en latín que tituló Actius (1499) pensando en su amigo Jacopo Sannazaro, que era conocido con ese nombre en la Academia. Pontaniana. Es un diálogo que nutrió muchas de las poéticas del siglo siguiente y del que por ejemplo se aprovechó Fernando de Herrera en sus Anotaciones (Sevilla 1580) sobre un poeta que precisamente pasó los últimos años de su vida en Nápoles².

Los autores de la primera mitad del siglo XVI que nacieron o residieron en esa ciudad italiana también frecuentaron la misma Academia (ya en el palacio de Scipione Capece o ya en Leucopetra) y siguieron sintiendo la misma devoción por Virgilio que sus antecesores: mantuvieron, por ejemplo, un intenso debate sobre el comentario de Donato a la Eneida. Teniendo muy presentes los versos de esa obra en todas sus tertulias no ha de sorprender que la mayoría de esos poetas, como veremos en seguida, se dedicara a recrearlos y reescribirlos en muchos de sus textos. Dos de esos poetas prestaron especial atención a un lugar del Hades que Virgilio parece inventarse (a partir de alguna sugerencia del canto 11 de la Odisea) y describir con bastante detalle: los "lugentes campi" rodeados por un bosque de mirtos. No fueron ellos los primeros en fijarse en ese conocido episodio de la Eneida (ya antes Dante y Petrarca lo habían tenido en cuenta en sus dos obras más alegóricas) pero sí abrieron el camino para una imitación más literal (el Cariteo, contemporáneo de Sannazaro, lo hizo entre los poetas de la Academia Pontaniana).

Los dos poetas de los que estudiaremos varios de sus sonetos, Luigi Tansillo y Berardino Rota, compartieron también en Nápoles el verso y la espada

${ }^{1}$ Véase al respecto el magnífico libro de M. J. Vega Ramos, El secreto artificio: "Qualitas sonorum". Maronolatría y tradición pontaniana en la poética del Renacimiento, Madrid 1992; y E. Fosalba Vela, "Implicaciones teóricas del alegorismo autobiográfico en la égloga III de Garcilaso. Estancia en Nápoles”, Studia Aurea 3, 2009, 54.

2 Para la influencia de Pontano sobre Herrea, véase J. F. Alcina Rovira, "Herrera y Pontano: la métrica de las Anotaciones", NRFH 32,1983, 340-54, B. Morros, Las polémicas literarias del siglo XVI: a propósito de Herrera y Garcilaso, Barcelona 1998; y M. J. Vega Ramos, El secreto artificio: "Qualitas sonorum". 
con Garcilaso de la Vega. Los dos (caso excepcional en poesía) exaltaron el amor conyugal ${ }^{3}$, pero también quisieron recordar en sus versos otras mujeres excepcionales que no situaron en el mismo lugar del Hades: una de ficción y otra de carne y hueso. La primera es la reina de Cartago que se suicidó por amor y la segunda Irene de Spilimbergo que murió cuando aún no había cumplido los veinte años.

Luigi Tansillo había nacido al igual que Horacio en Venosa, pero residió la mayor parte de su vida en Nápoles, donde entabló una honda amistad con el toledano, a quien llegó a querer como a un hermano ${ }^{4}$. Escribió sonetos de géneros y facturas muy diferentes, entre los cuales incluyó bastantes que concibió como ocasionales pero que en realidad no lo son. En uno de estos últimos se dirigió a una dama difunta que quería volver a morirse al darse cuenta de que un hado adverso le había arrebatado a su amante y otro al que llama "secondo" (en el sentido de "favorable' pensando no en sí misma sino en su rival) había puesto a su amante en brazos de otra mujer. El epígrafe que improvisó su editor, Erasmo Pèrcopo, aún hace más incomprensible el poema al mencionar un marido del que no hay ninguna referencia en ninguno de sus versos: "Ad una donna già morta, che per un dolore toccato al marito vorrebbe remorire». Vale la pena leer el soneto entero para poder entenderlo y reinterpretarlo en todos sus términos:

Se l'alme, sgombre dal terrestre pondo,

E varcate di Stige all'altra riva,

Ovunque sian, legge fatal non priva

D'udir, talor, quel che si fa nel mondo;

Ben proverá quell'alma duol profundo,

Ch’amò piú voi che la sua spoglia viva,

Quando saprà che'l ben di che l'ha priva

Avverso, or dona altrui fato secondo.

Se in parte, ove doler si possa ancora,

Ne la selva de' mirti, umbrosa e folta,

O ne'campi del pianto è la dimora;

Forse che si dorrà ch'oggi sia sciolta

Dal corpo, acciò che, qual di ferro allora,

Morir di duol potesse un'altra volta. ${ }^{5}$

${ }^{3}$ Para el amor conyugal en la poesía de Boscán, véase B. Morros, "El Canzoniere de Boscán (Libro II, Barcelona, 1543)", Revista de Filología Española 85, 2005, 252-58; y "La moralización del Leandro de Boscán: origen, difusión e interpretación de una fábula”, Studia Aurea 7, 2013, en prensa.

${ }^{4}$ Véase Fosalba, "Implicaciones teóricas del alegorismo autobiográfico en la égloga III de Garcilaso. Estancia en Nápoles”, 98.

${ }^{5}$ E. Pèrcopo (ed.), Il Canzoniere edito ed inedito secondo una copia dell'autografo ed altri manoscritti e stampe, Tipografia degli Artigianelli, vol. 2, Nápoles 1926; reproducción 
Para el soneto Tansillo ha tenido en cuenta el paisaje del Hades que ha leído en el libro 6 de la Eneida de Virgilio. Menciona tres lugares claves en ese paisaje: la laguna Estigia con la barca de Carón, los campos del llanto y la selva de mirtos. En esos lugares sabe que el alma conserva el recuerdo de su vida anterior y que incluso experimenta el mismo dolor o idénticos cuidados que antes de morir. No está identificada, hasta donde alcanzo, la dama a quien podría haber dedicado el soneto porque tal vez el poeta napolitano haya pensado en una o varias de las que pueblan el paisaje que halla descrito en el poema latino.

Para reconocer esos lugares con sus personajes característicos conviene recordar el descenso que Eneas hace al Hades en compañía de la Sibila para reencontrase con su padre. El troyano llega primero al río Aqueronte y a la laguna Estigia para subir en la barca del anciano Caronte a bordo de la cual emprende la travesía a la otra orilla. Cuando logra alcanzarla ha de hacer frente al guardián de los infiernos: el enorme perro Cerbero con tres gargantas. La Sibila lo duerme y Eneas se aleja de la orilla para dirigirse a la entrada donde oye las almas de los niños que habían muerto antes de tiempo. No muy lejos halla a los que han perecido por falsa acusación y a los que se han suicidado. Enseguida llega a los campos de los que lloran donde encuentra a la sombra de una selva de mirtos a los que han sufrido por un duro amor:

Non procul hinc partem fusi monstrantur in omnem

Lugentes campi; sic illos nomine dicunt.

Hic quos durus amor crudeli tabe peredit

Secreti celant calles et myrtea circum

Silva tegit: curae non ipsa in morte relinquunt (Aen. 6.440-4). ${ }^{6}$

'No lejos de aquí se muestran extendidos por una y otra parte los campos de los que lloran; así se los llama. A estos a los que el duro amor ha consumido con una peste cruel ocultan las sendas secretas y en derredor una selva de mirtos los cubre: los cuidados no los abandonan en la misma muerte.'

Es en esos «lugentes campi» donde Eneas contempla las sombras de damas que por distintos motivos han sufrido por amor: Fedra, Procris, Erifila, Evadne, Laodamia, Ceneo (muchacho que en el mundo de los muertos recuperó la

facsímil, Nápoles 1996, 207

${ }^{6}$ Los "lugentes campi" junto el segundo círculo de la Divina Commedia de Dante son los lugares elegidos, como veremos a continuación, por los poetas castellanos del siglo XV para situar sus particulares infiernos de amor (véase al respecto Miguel Ángel Pérez Priego, «Los infiernos de amor», en Iberia cantat. Estudios sobre poesía hispánica medieval, eds. Juan Casas Rigall y Eva María Díaz Martínez, Universidad de Santiago de Compostela 2002, 30911). El pasaje de Virgilio también lo había aducido G. Sobejano, "Aspectos del olvido en la poesía de Quevedo», en Homenaje a José Manuel Blecua, Madrid 1983, 640. 
forma de mujer $)^{7}$ y Dido. De las seis el héroe troyano pone su atención, como era de esperar, en la última, a la que ve vagando por un bosque espacioso con su herida aún fresca; se le acerca con lágrimas en los ojos para hablarle y justificar su conducta en Cartago:

Infelix Dido, verus mihi nuntius ergo

Venerat exstinctam ferroque extremam secutam?

Funeris heu tibi causa fui? (Aen. 6.456-8)

'Desgraciada Dido, ies verdad la noticia que me había llegado de tu muerte y ejecutada desesperada con hierro? ¿Fui yo, iay!, su causa?

Dido, para evitar su mirada, le vuelve el rostro y mantiene los ojos fijos en el suelo. Da la impresión de no estar ya aquejada por ese amor que fue la causa de su suicidio: no parece sufrir las "curae» propias del lugar en que se halla confinada9. Pero también es verdad que aparece en una actitud que recuerda la del ciervo herido que corre sin rumbo fijo con la herida abierta (es la máxima expresión del amante desesperado que ya Virgilio había usado anteriormente):

Inter quas Phoenissa recens a vulnere Dido

Errabat silva in magna... (Aen. 6.450-1)

'Entre las cuales la fenicia Dido vagaba por un gran bosque con la herida aún fresca...'

Pero la reina fenicia se aparta en seguida del héroe troyano con un gesto brusco para reunirse bajo los mirtos con su marido Siqueo, con quien comparte un mismo amor conyugal. Después Eneas, con mucha pena, reemprende su camino en su viaje por los infiernos en busca de la voz deseada de su padre.

${ }^{7}$ Para la influencia de Virgilio sobre Ovidio en el tratamiento del mito de Ceneo, véase $\mathrm{R}$. A. Smith, Poetic Allusion and Poetic Embrace in Ovid and Virgil, Michigan 1997, 74-78.

${ }^{8}$ Para este lugar del Hades Virgilio se ha inspirado en otro similar que describe Hom. $\mathrm{Od}$. 10.509-530 y 11.15-45. Circe al anunciarle a Ulises la necesidad de descender al Hades para conocer su futuro le describe los lugares que habrá de recorrer para penetrar en los dominios de Perséfone, con especial mención de los ríos que la rodean (el Aqueronte, donde desembocan el Piriflegetonte y el Cocito, y la laguna Estigia); Ulises al llegar al lugar indicado por la maga y tras los sacrificios correspondientes ve salir del Érebo entre otras las almas de "tiernas esposas con ánimo destrozado por recientes penas ( $(\varepsilon \circ \pi \varepsilon v \uparrow ి \varepsilon \alpha)$ ) (39).

${ }^{9}$ Para el personaje de Dido, véase el libro clásico de María R. L. de Malkiel, Dido en la literatura española. Su retrato y defensa, Londres 1974, además de los artículos de R. G. Cañal, "Dido y Eneas en la poesía española del Siglo de Oro", Criticón 44,1988, 25-54, y V. Cristóbal, "Dido y Eneas en la literatura española”, Alazet, 14, 2002, 41-76. 
En la que es sin duda su mejor elegía (y escribió tantas buenas), Propercio ve en sueños la sombra (no el alma) de su amada Cintia, que le describe desde el más allá el mundo oscuro de la muerte que ya empieza a serle familiar: el río Aqueronte cuyas aguas circulan en direcciones opuestas llevando hacia un lado tanto las sombras de la adúltera Clitemnestra como la de Pasifae y hacia el otro tanto la de Andrómeda como la Hipermestra, las dos ejemplos de esposas fieles. Sin precisar ningún lugar en concreto pero en probable alusión a los «lugentes campi» virgilianos, Cintia menciona las lágrimas derramadas en el mundo de los muertos para restañar los amores de los vivos:

Sic mortis lacrimis vitae sanamus amores

'Así sanamos los amores de la vida con las lágrimas de la muerte'

La dorada Cintia termina su intervención refiriéndose a las puertas piadosas de los Campos Elíseos que permiten a las sombras el regreso a la tierra. Se despide anunciándole a su poeta que en la inmortalidad lo tendrá para ella sola sin compartirlo con ninguna otra. Parece imaginarse un lugar donde poder prolongar su amor más largo que la muerte y quizá también que el olvido: un lugar en que con las lágrimas de los dos restañar las infidelidades cometidas en vida. No parece que ese lugar pueda ser otro que los «lugentes campi».

En una de las elegías del primer libro, Propercio somete a su amor por Cintia a una prueba cuya superación le garantiza una inmortalidad que no podría alcanzar de otro modo. Se lo imagina pasando de un lado a otro de la ribera de un río al que no llega a identificar:

Illic, quidquid ero, semper tua dicar imago:

Traicit et fati litora magnus amor (11-12).

'Allí, cualquier cosa que yo sea, siempre seré llamado tu sombra: y mi gran amor pasará al otro lado de las riberas de la muerte.'

Podía hacer referencia al primer río del Hades, el Aqueronte, que es el río de la muerte, pero también al río Leteo, que lo es del olvido. En los versos inmediatamente anteriores, ha aducido como ejemplo de fidelidad amorosa el de Protesilao, quien tras morir en la guerra de Troya pidió permiso a los dioses para regresar al mundo de los vivos y gozar durante tres horas de su esposa Laodamía. Propercio narra sólo en cuatro versos el viaje del héroe tesalio desde el más allá a su morada conyugal:

Illic Phylacides iucundae coniugis heros

Non potuit caecis immemor esse locis,

Sed cupidus falsis attingere gaudia palmis 
Thessalus antiquam venerat umbra domum (Prop. 1.19.7-10).

'Allá el héroe de Filacia, en los lugares oscuros, no ha podido olvidar a su encantadora esposa, sino que, deseoso de conseguir los goces con manos engañosas, llega el tesalio como una sombra a su antiguo hogar.'

El regreso al que alude el poeta latino es más verosímil si al difunto lo sitúa al otro lado del Aqueronte, en los «lugentes campi», que más allá del Leteo. Sólo en los campos en cuestión la sombra de Protesilao puede seguir amando a su esposa y puede plantearse el retorno; nunca tras cruzar el otro río, porque en sus aguas se habría olvidado de ella y se habría preparado para habitar otro cuerpo.

Para acabar de decidir el lugar en que Propercio imagina al tesalio conviene estudiar el adjetivo con que lo distingue: "caecis... locis». Este adjetivo, que indica que son lugares desprovistos de luz, encaja con los tipos de lugares en que Virgilio sitúa los «lugentes campi»:

Proxima deinde tenent maesti loca, qui sibi letum

Insontes perperere manu lucemque perosi

Proicere animas... (Aen. 6.433-5)

'Después los lugares vecinos están ocupados por los tristes que sin culpa se provocaron la muerte con su mano y, detestando la luz, abandonaron sus vidas...'

Es fácil concluir que los "caecis... locis» son los propios de los tristes que detestan la luz («lucemque perosi»), y que por tanto Propercio sitúa a Protesilao en los «lugentes campi». Pero no todo es tan sencillo como parece. Virgilio describe otros campos que distingue de los «loca» en los que ha colocado a los suicidas porque utiliza un superlativo ("ultima») con que se desmarca del anterior ("proxima»):

[Proxima... tenent... loca....]

Iamque arva tenebant

Ultima, quae bello clari secreta frequentabant (Aen. 6.477-8).

'Ya ocupaban los campos extremos, donde asistían apartados los famosos en la guerra.'

Virgilio no brinda información directa sobre esos campos pero pone en boca de uno de sus moradores los mismos adjetivos que había empleado para presentar los «lugentes campi»:

An quae te fortuna fatigat,

Ut tristis sine sole domos, loca turbida, adires? (Aen. 6.533-534) 
'¿o qué fortuna te persigue para hacerte venir a estos lugares confusos, moradas tristes sin sol?'

Propercio, pues, entiende los "caecis... locis» como estos «loca turbida», «sine sole domos", y acaba ubicando a Protesilao dentro de sus confines para hacerlo regresar desde ellos al mundo de los vivos. Es, sin embargo, en los otros campos, los «lugentes», donde ha hecho aparecer la sombra de Laodamía, la fiel esposa del héroe tesalio que se suicidó -tras pasar con él esas tres horas de placer que le regalaron los dioses-- para reunirse con su marido y amarlo definitivamente en el mundo de los muertos. Pero Virgilio no les ha asignado el mismo lugar en ese mundo porque los amantes habían muerto de manera muy diferente: describe a Laodamia sola en los "lugentes campi» porque supone al marido en los "arva [...] ultima», los campos propios de los guerreros que han caído en el campo de batalla. Si hace una excepción con Siqueo es quizá porque el marido de Dido no murió heroicamente sino asesinado por su cuñado.

En una época un poco más tardía, Ausonio compuso un breve poema $(\mathrm{Cu}$ pido cruciatus) en que narra el descenso de Cupido a los «lugentes campi» y su encuentro en sus dominios con una serie de heroínas que no pueden olvidar las desgracias que habían padecido en vida. Las heroínas lo reconocen nada más verlo aparecer y tras contemplar sus heridas hacen responsable a él de haberlas sufrido. Todas lo rodean y lo arrastran a un bosque de mirtos para crucificarlo en uno de sus árboles más altos. Incluso Venus participa en la tortura de su hijo al recordar que por su maldad se vio atrapada entre unas redes cuando compartía su lecho con Marte. Las heroínas al final deciden liberar a su prisionero porque prefieren culpar a los hados de sus desdichas.

En el prefacio en prosa que incluye al principio del poema Ausonio se dirige a un personaje desconocido a quien llama "hijo" no en sentido literal sino más bien afectuoso. Le confiesa que ha compuesto su obra (a la que llama "eclogae") a partir de un cuadro en que había visto a Cupido crucificado por algunas de las heroínas que Virgilio había situado en los «lugentes campi»:

Treveris quippe in triclinio Zoili fucata est pictura haec: Cupidinem cruci affigunt mulieres amatrices, non istae de nostro saeculo, que sponte peccant, sed illae heroicae, quae sibi ignoscunt et plectunt deum, quorum partem in lugentibus campis Maro noster enumerat. ${ }^{10}$

'En Treveris en efecto, en el comedor de Zoilo, hay esta pintura: mujeres enamoradas clavan a Cupido en la cruz, y no son como estas de nuestra época, que pecan

${ }^{10}$ A. Pastorino, Decimo Magno Ausonio, Opere, Turín 1971, 596. Véase al respecto N. Gregson Davis, "Cupid at the Ivory Gates: Ausonius as a Reader of Vergil's Aeneid", Colby $Q$ 30, 1994, 162-70. 
de buen grado, sino aquellas heroínas que se perdonan a sí mismas y castigan al dios, algunas de las cuales menciona nuestro Marón en los campos de los que se lamentan.'

Al principio de su poema Ausonio vuelve a citar a Virgilio al describir el lugar en el que transcurre la acción y al mencionar a las heroínas que en medio de lágrimas lo recorren mostrando aún las señales de la muerte que sufrieron (al igual que hace Dido en la Eneida):

Aëris in campis, memorat quos musa Maronis,

Myrteus amentes ubi lucus opacat amantes,

Orgia ducebant heroides et sua quaeque,

Ut quondam occiderant, leti argumenta gerebant,

Errantes silva in magna et sub luce maligna [...]

Omnia quae lacrimis et amoribus anxia maestis

Exercent memores obita iam morte dolores:

Rursus in amissum revocant heroidas aevum. ${ }^{11}$

'En los campos aéreos, que la musa de Marón nos recuerda, donde un bosque de mirtos da sombra a los locos amantes, las heroínas celebraban sus misterios y, errando por el gran bosque y bajo una luz escasa, cada una llevaba las marcas de la muerte que en otro tiempo había sufrido [... Todas las que angustiadas por las lágrimas y los tristes amores recuerdan en la muerte después de muertas los dolores: las heroínas vuelven a evocar la vida perdida.'

Ausonio también decide que las heroínas crucifiquen a Cupido en el mismo árbol de un bosque de mirtos en que Proserpina había crucificado a Adonis por haberla desdeñado en vida y por seguir amando después de su muerte a Venus:

Eligitur maesto myrtus notissima luco,

Invidiosa deum poenis. Cruciaverat illic

Spreta olim memorem Veneris Proserpina Adonim. ${ }^{12}$

'Se eligió en este triste bosque un mirto famosísimo, odiosa venganza de los dioses.

Proserpina crucificó desdeñada allí en otro tiempo a Adonis, que aún se acordaba de Venus.'

En su soneto Tansillo empieza describiendo la liberación del alma de la dama que se dispone a subir a la barca de Carón para cruzar la laguna Estigia. Aclara que el alma, tras llegar a la otra orilla, sigue recordando la vida ante-

${ }^{11}$ Ausonio, Opere, 596-8.

${ }^{12}$ Ausonio, Opere, 602. 
rior: no hay ninguna ley fatal que le prive de oír cuanto ocurre en el mundo terrenal. En ese punto deja claro que el alma de la dama experimentará dolor cuando sepa que su amante, al que amó más que a sus vivos despojos, está con otra mujer. Al imaginarla aún enamorada y celosa de otra dama la sitúa en el mismo lugar que Virgilio había reservado a quienes no abandonan sus cuitas amorosas ni con la muerte. El lugar, al igual que el poeta latino, lo identifica como el campo de los que lloran y la selva de los mirtos:

Se in parte, ove doler si possa ancora,

Ne la selva de' mirti, umbrosa e folta,

O ne'campi del pianto è la dimora;

En ese primer terceto Tansillo ha traducido bastante al pie de la letra algunos de los versos de Virgilio: "myrtea... silva» ("la selva de "mirti"») y «lugentes campi» ("campi del pianto»), pero también "partem» («in parte») y "curae non ipsa in morte relinquunt» ("dove doler si possa ancora»). El poeta de Venosa no parece haber diferenciado los "campi del pianto" de la "selva de' mirti”, porque los concibe como dos partes de un mismo lugar (ha visto a Dido recorrer los primeros para descansar junto a su marido bajo la sombra de los árboles de Venus).

En la Divina commedia, Dante había descrito con detalle el paisaje de lo que él llama infierno pensando siempre en esos versos de la Eneida (no sin motivo se hace acompañar por su autor en ese viaje hacia la muerte y el olvido pero también hacia el amor imposible). Describe para empezar el río Aqueronte y la barca en la que Caronte conduce todas las almas a la otra orilla; menciona a continuación, ya en el primer círculo, el valle en que sitúa las almas de quienes murieron antes de la llegada de Cristo; después, en el segundo, se refiere a un lugar privado de toda luz en que pone las almas de los lujuriosos que no dejan de llorar: es el círculo en que incluye a damas y héroes de la antigüedad (por supuesto, Dido), también medievales (Tristán) y contemporáneos (Francesca y su cuñado Paolo). Se detiene en su paisana a quien atribuye unos versos con los que recuerda el lugar tan especial que habita:

Amor, ch'a nullo amato amar perdona,

Mi prese del costui piacer sì forte,

Che, come vedi, ancor non m'abbandona $(5.103-5)^{13}$.

El poeta de Beatriz, que sin duda envidia a Francesca, recuerda los «lugentes campi» en que Virgilio imagina las almas de los que en sus ocultos senderos no han podido abandonar tras la muerte sus preocupaciones amorosas: «curae

${ }^{13}$ D. Matalia, Dante. Divina Commedia, Milán 1975, 122. 
non ipsa in morte relinquunt» ${ }^{14}$. Ha introducido un cambio más o menos importante con respecto al poema latino al convertir las "curae» ('penas, cuidados por amor') en "Amor [...] del costui piacer» ('Amor [...] inspirado por la belleza placentera de ese [Paolo]'), pero, en cambio, ha interpretado de modo bastante fiel «relinquunt» («m'abbandona»), con la sola modificación del número del sujeto ("curae» y "Amor [...] del costui piacer» respectivamente) ${ }^{15}$. No sé si ha pretendido adaptar la expresión "amor durus" ("amor irresistible, irrefrenable'), utilizada, como hemos visto, por Virgilio para caracterizar el amor de las sombras que habitan los «lugentes campi»; o también habrá podido tener en cuenta los versos en que Propercio narra el retorno de Protesilao, quien había muerto en la guerra de Troya, al hogar conyugal para gozar por unas horas de Laodamía. El amante de Cintia insiste en presentarlo en los «caecis... locis» sin haberse podido olvidar de los «gaudia» 'goces, placeres ${ }^{\text {'16, }}$, aunque, como hemos visto antes, no acaba de identificar esos oscuros lugares con los «lugentes campi».

Uno de los mejores (y también fueron muchos) comentaristas de Dante, Benvenuto da Imola, sitúa el verso dentro del tópico del amor más allá de la muerte pero no lo relaciona con el de Virgilio:

quia sicut videre potes ita sumus ligati simul amore post mortem sicut fuimus in vita. ${ }^{17}$

'porque puedes ver que así como somos apresados por el amor después de la muerte como lo fuimos en vida.'

Antes de presentar a Francesca y Paolo, Dante se ha referido al lugar en el que los dos amantes han conservado el mismo deseo que en vida como un lugar en que el poeta se ha sentido golpeado por el llanto (es realmente un «campo di pianto»):

${ }^{14}$ El primer comentarista en darse cuenta de esta deuda más que evidente fue Bernardio Daniello (1547-1568): "Che, il quale piacer, ancor non m'abbandona, percioche ancora lo amava di là; onde è scritto da Virg. Nel sesto dell'Eneide: 'curae non ipsa in morte relinquunt”; Niccolò Tommaseo (1837) volvió a señalarla: "Abbandona: Aen., VI: "curae non ipsa in morte relinquunt”. Estos comentarios junto a todos los demás sobre la Divina Commedia pueden leerse en Darmouth Dante Project: dante.darmouth.edu.

${ }^{15} \mathrm{Al}$ estudiar las posibles relaciones entre el Hades virgiliano y el infierno dantesco, M. Á. Pérez Priego, "Los infiernos de amor", 311-3, no señala esta clara influencia del uno sobre el otro.

${ }^{16}$ El problema radica en poder demostrar si Dante pudo o no haber leído esos versos de Propercio. Se han conservado un manuscrito del siglo XII y varios del XIII (uno procedente del que poseyó Petrarca) con casi todas las elegías (véase Antonio Tovar, Introducción a Propercio, Elegías, Barcelona 1963, xlvi-xlvii).

${ }^{17}$ Es el Comentum super Dantis Aldigherii Comediam, en Biblioteca Italiana, 2005. 
Ora incomincian le dolenti note

A farmisi sentire; or son venuto

Là dove molto pianto mi percuote $(5.25-7)^{18}$.

Tampoco en esos versos el comentarista Benvenuto de Imola plantea la posibilidad de una más que probable alusión a esos tan característicos lugares virgilianos en que los amantes no dejan de llorar para con sus lágrimas redimir los excesos y errores cometidos en vida.

Francesco Petrarca podía haber aludido también a los «lugentes campi» en uno de los sonetos en que se plantea la posibilidad del suicido para poner fin al "pensiero amoroso" que tanto le aflige. Si la descarta es porque teme que en el lugar en el que se imagina después de su muerte seguirá llorando al igual que lo hacía en vida y padecerá también la misma guerra que antes:

S'io credesse per morte essere scarco

Del pensiero amoroso che m'atterra,

Colle mie mani avrei già posto in terra

Queste membra noiose, et quello incarco;

Ma perch'io temo che sarebbe un varco

Di pianto in pianto, et d'una in altra guerra. ${ }^{19}$

El aretino puede estar dando a entender que son dos los lugares que prevé para su alma en el otro mundo después de haberse suicidado: el infierno cristiano y los clásicos «lugentes campi». Teniendo en cuenta los dos primeros versos del soneto parece decantarse por los campos virgilianos porque esos son lugares que ocupan las almas que no sufren más tortura que la de llorar por un amor que no han conseguido extinguir ni con la muerte (en el infierno cristiano, como en el Tártaro clásico, las almas lloran no por amor sino por los castigos y daños físicos que reciben por sus habitantes). Nótese el juego de palabras que introduce a partir de la metáfora del pensamiento amoroso como un peso insoportable: 'si creyera que con la muerte me liberaría de un peso que me derriba, yo ya me habría ocupado con mis manos de derribar ese peso'.

En el triunfo de amor, Petrarca alude claramente a los bosques del mirto que rodean los campos del llanto porque sitúa bajo sus sombras a las almas de amantes famosos que no dejan de lamentarse y llorar:

Odi'l pianto e i sospiri, odi le strada

De le misere accese, che li spirti

Rendero a lui che'n tal modo gli guida.

${ }^{18}$ Matalia, Dante. Divina Commedia, 36-37.

${ }^{19}$ M. Santagata, Francesco Petrarca, Canzoniere, Milán 1996, 189 (en n. a los versos 5-6 el editor aduce el verso de Aen. 6.444). 
Non poria mai di tutti il nome dirti,

Ché non huomini pur, ma dèi gran parte

Empion del bosco e degli ombrosi mirti $(1.145-50)^{20}$.

Se ha de tener en cuenta que esta descripción forma parte de una visión que tiene Petrarca tras tumbarse en la hierba vencido por el sueño. Es en ese estado en el que ve llegar montado en un carro como si fuera un emperador romano a Cupido que arrastraba a su alrededor a toda clase de amantes, vivos y muertos.

El poeta barcelonés afincado en Nápoles, Benedetto Gareth, conocido como el Cariteo en la Academia Pontaniana, incluye en su Endimione (Nápoles 1506), una canción en que se presenta errando por los lugares más oscuros del Hades, muy lejos de los Campos Elíseos, pero también de la selva de los mirtos, por culpa de amor:

Canzone, io non fui mai

Nei campi Elisi et fortunate valli,

Ov'altro sol si vede et altra luna,

Né mai l'aëre imbruna,

Né vivo ascoso in questi secreti calli

Coverti d'amorosi, ciprii mirti;

Ma son più giù tra più dolenti ${ }^{21}$

El Cariteo también parece seguir directamente el pasaje de la Eneida que he citado y parafraseado antes: los «secreti calli» es una traducción literal de "secreti... calles», así como "ascoso... coverti d'... mirti», de "celant... et myrtea circum/ silva tegit»; ha querido dejar claro que el mirto es árbol consagrado a Venus al anteponerle dos adjetivos que así lo subrayan: "amorosi, ciprii mirti». En ese recorrido por el Hades, no ha elegido el lugar donde están quienes han sufrido en vida por amor sino otro en que no pueden poner el pie los que han sido puros de corazón. Es la región, el Tártaro, en la que padecen personajes como Ticio, Sísifo o Tántalo. El barcelonés ha de tener en mente a una Dido enamorada cuando se presenta a sí mismo en esa misma actitud que justifica por ser víctima de Cupido:

Errando sol per antri horrendi et foschi $[\ldots]$

mi mena Amor... (2.1-6).

${ }^{20}$ M. Santagata, Francesco Petrarca, Trionfi. Rime estravaganti. Codice degli Abbozzi, Milán 1996, 87-8.

${ }^{21}$ Erasmo Pèrcopo, Le Rime di Benedetto Gareth il Chariteo, Nápoles 1892, 25. 
Bernardo Tasso, amigo también de Garcilaso, incluyó en el libro tercero de sus Amori (Venecia 1537), la "Favola di Leandro e d'Ero", en el que recrea el epilio de Museo, bien directamente del original griego, impreso por primera vez hacia 1495, o bien a través de algunas de sus versiones latinas, la de Aldo Manuzio, en una edición bilingüe de 1497 o 1498, o la de Guillermo de Mara, en una edición de 1511. En los últimos versos del poema, tras haber narrado la muerte de los dos amantes, se los imagina cruzando el río de la muerte (en este caso directamente el Cocito, que era un afluente del Aqueronte) para dirigirse a los Campos Elíseos o quedarse en la selva de los mirtos:

Donate i corpi morti a sepultura,

Acciò possin varcar insieme aggiunti

Le nere e torbid'acque di Cocito,

E gira i lieti e fortunati campi,

O pur nel bosco degli ombrosi mirti (vv. 671-5)22.

Para este final no se ha podido inspirar en el poema de Museo porque el gramático griego lo termina con la narración del suicidio de Hero. Debía estar asociada a la leyenda en sí porque el poeta valenciano Roís de Corella, que la recrea hacia 1460 en una de sus prosas mitológicas, la Història de Leànder i Hero, también se refiere a la vida ultraterrena de las almas de los dos amantes:

E no penses, ànima mia de Leànder, llarg espai io et detenga; comporta que al teu cos meu io done sepultura, i aprés, ensems ab la mia, davallaràs als regnes de Plutò, perquè un carçre, una pena, unes cadenes, après de la mort lliguen aquelles dos ànimes, les quals una amor havia lligat en vida; e així, les cossos morts, abraçats, estaran en un sepulcre, e nosaltres, en dolor vivim, junts en una pena. ${ }^{23}$

Es verdad que Corella no ofrece ningún dato explícito con el que indique el lugar del Hades que asigna a los dos amantes, pero resulta fácil concluir que no está pensando en otro que los «lugentes campi», porque sabe que en esos campos se quedan las almas de quienes conservan el mismo amor que en vida y porque posiblemente también ha leído el poema (Cupido cruciatas) de Ausonio, quien menciona a Hero entre las heroínas que en los «lugentes campi» atormentan a Cupido (vv. 22-4). Tampoco ignora que Virgilio ha situado en ellos a Dido compartiendo el mismo tipo de amor conyugal con

${ }^{22}$ D. Chiodo, Bernardo Tasso, Rime, Turín 1995, I, 411.

${ }^{23}$ J. L. Martos, Les proses mitològiques de Joan Roís de Corella, 179; véase S. M. Cingolani, Joan Roís de Corella. La importància de dir-se honest, València 1997, 184; y J. L. Martos, Fonts i cronología de les proses mitologiques de Joan Roís de Corella, València 2001, 70-1. 
Siqueo, que es precisamente el tipo de amor que también ha pensado para Leandro y $\mathrm{Hero}^{24}$.

En otra de sus prosas mitológicas, las Lamentacions, Corella sitúa a los personajes que exponen sus quejas claramente bajo las "myrtae... silva» que envuelven los «lugentes campi». Confiesa haber llegado a esos campos tras descender a los «trists e tenebrosos palaus de Plutó» y seguir el camino que la Sibila mostró a Eneas:

E, així, só arribat en aquell adolorit verger, en lo qual los devots de Venus, en continu plor, lurs penes reconten... ${ }^{25}$

El valenciano crea una palabra nueva para referirse al lugar en cuestión uniendo las palabras "lugentes» y "silva» («adolorit verger») y llama a sus habitantes «devots de Venus» porque la «silva» lo es de «myrtea», que es árbol consagrado a Venus.

Boscán, en cambio, para su versión de la fábula de Leandro y Hero, sigue el poema de Bernardo Tasso, del que suprime la alusión a la selva de los mirtos, posiblemente porque pretende salvar a los dos amantes al haber insistido en que el suyo no era un amor loco sino un amor legítimo y conyugal:

Y así fueron juntas las dos almas

A los Campos Elíseos para siempre $(2792-3)^{26}$

Bernardo Tasso podía haberse leído estos versos del barcelonés cuando entre los cincuenta poemas que compone "in morte della moglie" (ocurrida en febrero de 1556) y reproduce en el libro quinto de sus Rime (Venecia, 1560) incluye una canción a la que al final le pide que busque el alma de su esposa (Porzia de' Rossi) no en la selva de los mirtos sino en los Campos Eliseos:

Se di volar al ciel così secure

Penne, canzona, e destri vanni avrai,

Non ne la selva degli ombrosi mirti,

Ma fra i beati spirti

Più cari a Dio, la mia donna vedrai;

Dille: --Chi t'amò qui, lassù t'onora,

${ }^{24}$ Véase sobre ese aspecto de la Història de Corella el magnífico y muy documentado trabajo de J. Pujol, "Per a les fonts de la Història de Leànder i Hero de Joan Roís de Corella: la 'lleugera ombra' de l'heroi i la mort de l'heroïna", Cultura Neolatina, en prensa.

${ }^{25}$ J. L. Martos, Les proses mitològiques de Joan Roís de Corella, 175, y "El programa moral de les Lamentacions i els lugentes campi", en Fonts $i$ seqüencia cronològica de les proses mitològiques de Joan Roís de Corella, Alacant 2001, 57-106.

${ }^{26}$ C. Clavería, Juan Boscán. Obra completa, Madrid 1992, 324. 
Lassso ti chiama e ti suspira ignora (vv. 92-8)27.

Tasso ha valorado más el amor conyugal con Porzia que el de Leandro y Hero al no dudar en ningún momento sobre el lugar que en el más allá había de ocupar su esposa.

Otro poeta napolitano, Marco Antonio Epicuro, en una "favola boschereccia" (así la llama el propio autor), que titula Mirzia y que llegó a componer en, presenta a uno de los pastores de la obra, Filerio, asegurando a su ninfa Venalia que si sigue desdeñándolo llegará pronto a la selva de los mirtos (de algún modo le garantiza que no sólo que por ella morira sino que también la amará después de la muerte):

Vedi che vado, e non con lento passo,

A trovar l'ombra degli ombrosi mirti

Là giù nel regno tenebroso e basso. ${ }^{28}$

En su tratado de mitología, titulado Le imagini degli dei degli antichi (Venecia 1556), Vincenzo Cartari traduce libremente al final del extenso capítulo que dedica a Cupido (el 14) el poema de Ausonio (prefiere por ejemplo el adjetivo "maestis" al "aeris" que su modelo toma literalmente de la Aen. 6.887):

Ne i mesti campi, dove i verdi mirti

Fanno la selva ombrosa, ch'in se chiude

Gl'innamorati, et infelici spirti,

Eran l'alme ch'in se fur empie, e crude

Per troppo amar'altrui si ch'anzitempo

Della spoglia mortal restaro ignude.

E la memoria del passato tempo

Ritrovando mostrava ciascheduno

Come, e perche morì cosi per tempo.

Ha la gran selva poca luce, e bruna,

Come talhor ch'oscuro vel nasconda. ${ }^{29}$

Cartari insiste en que son almas que han amado demasiado y que han muerto antes de tiempo (quizá para dar a entender que se han suicidado). Pensando en los famosos versos de Francesca en el canto V del Inferno de Dante ("Nessum maggiore dolor [...]"), presenta a los ocupantes de esos campos recordando el tiempo pasado y la razón por la que han muerto.

27 Tasso, Rime, 172-3.

${ }^{28}$ Marco Antonio Epicuro, Mirzia, III, 4, en Biblioteca italiana, 2003

${ }^{29}$ Vicenzo Cartari, Le imagini degli dei degli antichi, Venecia 1625, 380-1. 
En uno de los sonetos que coloca al principio de sus Rime et prose (Venecia 1558), Giovanni della Casa se dirige a los celos para pedirles que salgan de su corazón y vuelvan a los «lugentes campi» donde se los imagina lamentándose de si mismos, pasando los días sin reposo y las noches sin sueño:

Cura, che di timor tu nutri e cresci,

E più temendo maggiore forza acquisti,

E mente con la fiamma il gelo mesci,

Tutto'l regno d'Amor turbi i contrsiti;

Poi che'n brev'ora entro al mio dolce hai misti

Tutti gli amari tuoi, del mio cor esci;

Torna a Cocito, a i lagrimosi e tristi

Campi d'inferno; ivi a te stessa incresci,

Ivi senza riposo i giorno pasa,

Senza sonno le notti, ivi ti duoli

Non men di dubbia che di certa pena.

Vattene: a che più fera che non suoli,

Se'l tuo venen m'è corso in ogni vena,

Con nove larve a me ritorni e voli? $?^{30}$

Della Casa supone en esos campos, a pesar de saber que carecen de luz, la existencia de día y de noche (como ya había hecho también el marqués de Santillana) porque ha leído en la Eneida que la Sibila advierte al troyano, cuando los dos están en otros campos más distantes pero igualmente oscuros, que la tarde está llegando a su fin y que no pueden perder más tiempo en su visita al otro mundo (6.538-9). El poeta italiano parece situar a los celos en ese lugar del Hades para que de algún modo ellos mismos padezcan lo que él había padecido cuando aún los tenía en su corazón.

En uno de sus diálogos (Sopra due cuestione amorose), Torquato Tasso vincula (por si hubiera alguna duda) el famoso bosque de los mirtos con el descenso de Virgilio al Hades porque sitúa bajo sus sombras a los amantes "incontinenti" para diferenciarlos de los "intemperanti" o "viziosi", a los que supone dentro de la ciudad, víctimas de las peores penas y castigos:

Ed in ciò seguire l'autorità di Virgilio, il quale gli mette nel bosco degli ombrosi mirti, fuori della città de' Dite. ${ }^{31}$

En el libreto que Alessandro Striggio hijo escribe para la ópera La favola di Orfeo que Claudio Monteverdi estrenó el 24 de febrero de 1607, el personaje

${ }^{30}$ Giovanni della Casa, Rime et prose, Venecia 1574, 8 .

${ }^{31}$ Discorsi di Torquato Tasso, Pisa 1823, I, 110. 
alegórico de la Esperanza le refiere los lugares del Hades que el mítico músico habrá de atravesar hasta llegar a la morada de su querida Eurídice:

Ecco l'atra palude, Ecco il nocchiero

Che trae l'ignudi spirti $O$ l'altra sponda

dov'ha Pluton de l'ombre il vasto impero.

Oltre quel nero stagni, Oltre quel fiume,

In quei campi di pianto e di dolore

Destine crudele ogni tuo ben t'asconde. ${ }^{32}$

Striggio parece seguir bastante puntualmente el pasaje de la Eneida que he glosado arriba con la única excepción de ubicar el río Leteo antes de los «campi di pianto». Describe primero la laguna Estigia («atra palude» y «nero stagni») con su barquero Caronte, después el río Leteo y por último los mencionados "campi». No creo que el autor del libreto identifique "quel Fiume» con el río Aqueronte porque Virgilio parece confundirlo con la laguna Estigia.

En La Galeria (1619) Giovan Battista Marino solo menciona uno de los dos lugares (la selva de los mirtos) en el que ubica a las almas quejándose aún de su dolor y al que supone que bajará el poeta Battista Guarini para consolarlas:

Oimè, piangete, o fonti,

Che piú tra voi non sona

Del buon Cantor la fistula famosa;

Ma da l'alto Helicona

Scesa è laggiú dentro la selva umbrosa

De verdeggianti mirti

A consolar gli sconsolati spirti. ${ }^{33}$

En su gran obra, el Adone (París 1623), en la que trabajó veinte años, Marino pone también en boca de Polifemo una alusión también a la famosa selva de los mirtos en la que imagina al amante de Galatea inundándola con sus lágrimas:

Teme non cresca al mio gran pianto Averno

E de' mirti amorosi inondi il bosco.

Teme non beva in Lete un dolce oblio

Sich’io più non rimembri il dolor mio (229). ${ }^{34}$

${ }^{32}$ Alessandro Striggio, L'Orfeo favola in musica, http:/www.librettidopera.it/zpdf/Orfeo.pdf, musiche di Claudio Monteverdi, 14/29

${ }_{33}$ Giovan Battista Marino, en Biblioteca italiana, 2003: www.bibliotecaitaliana.it/exist/ biblit/-

${ }^{34}$ Este poema mitológico aparece editado en Biblioteca Italiana, 2004. 
En unos versos anteriores se había referido a los campos del llanto (sin darle el nombre que aparece en Virgilio) en los que supone al cíclope, tras su muerte, con las mismas penas de amor que en vida:

Di morir bramo e non sperando ho speme

Di finir, con la morte, i gran martiri (227).

Considera que Polifemo sólo dejará de sufrir sus dolores por el amor a Galatea cuando haya bebido las oscuras aguas del olvido. Primero ha mencionado el río Aqueronte (no la laguna Estigia), después el Cancerbero y finalmente (en los versos citados) la selva de los mirtos y el río Leteo.

Los poetas castellanos del siglo XV y principios del XVI compusieron infiernos de amor tomando como punto de partida los versos comentados de la Eneida y el canto V de la Divina Commedia, pero ninguno de ellos se refiere directa y claramente a los «lugentes campi» o "silva... myrthea». El marqués de Santillana, por ejemplo, no describe ninguno de esos dos lugares porque prefiere situar a los amantes en el castillo de los sabios. Amplía la lista de sus dos fuentes principales y los presenta a todos como Virgilio a Dido en los «lugentes campi» («recens a vulnere Dido errabat»):

E por el siniestro lado

Cada cual era ferido

En el pecho, e foradado

De grand golpe dolorido $(57.449-52)^{35}$.

En el Bías contra Fortuna, se atiene más puntualmente a los escenarios del Hades descritos en la Eneida, pero parece ubicar los campos en cuestión en el Tártaro al suponer en ellos a los que forzaron a sus familiares y a los que ofendieron a los dioses:

Nin las voces de Flegías

Me farán algun espanto

En aquel horrible llanto

Que todas noches e días

Facen los que corrompieron

Sus deodos

E por otros tales modos

A los dioses ofendieron $(162)^{36}$.

${ }^{35}$ Moreno y Kerkhof, Obras completas, 152.

${ }^{36}$ Moreno y Kerkhof, Obras completas, 329. 
Cuando describe a los que en ese lugar se pasan las noches y los días llorando (como hará también Berardino Rota en su soneto a Irene) se está refiriendo a los que se hallan en los «lugentes campi» porque en ningún otro sitio los condenados se muestran con esa actitud.

En su infierno de amor, Garci Sánchez de Badajoz tampoco menciona esos campos pero deja claro que sus personajes vagan entre sus límites al presentarlos con el mismo tipo de amor que cuando estaban vivos. Al incluir entre sus moradores al poeta Juan de Mena le atribuye parte de las palabras que Virgilio había empleado para aludir a las preocupaciones amorosas que todos ellos conservaban después de la muerte («curae non ipsa in morte relinquunt», 'ni los cuidados dejan en la misma muerte'):

Y vi luego a Juan de Mena

De la edad que amor sintió,

Con aquella misma pena

Como cuando lo encantó

El amor en su cadena,

Y de tal llaga herido,

Que le privaba el sentido.

Y así estaba trasportado,

Diciendo como olvidado:

'iay, dolor del dolorido

Que no olvida cuidado!' (vv. 111-21) $)^{37}$

Es posible que el antiguo autor de La Celestina también haya tenido en cuenta ese escenario del Hades cuando pone en boca de un desesperado Calisto, que ha buscado consuelo para el desdén de Melibea en la soledad y la oscuridad de su habitación, una referencia a las almas o espíritus de los conocidísimos amantes Píramo y Tisbe:

iOh piedad de Seleuco, inspira en el plebérico corazón porque, sin esperanza de salud, no envíe el espíritu perdido con el del desastrado Píramo y la desdichada Tisbe! ${ }^{38}$

Calisto pide para el corazón de Pleberio o de Melibea la misma piedad que la del padre (Seleuco) que por amor de su hijo (Antíoco) fue capaz de renunciar a su mujer (Estratonice) ${ }^{39}$. Es solo de esa manera cómo podrá evitar

37 J. Castillo, Cancionero de Garci Sánchez de Badajoz, Madrid 1980, 317.

${ }^{38} \mathrm{Nadie}$, que yo sepa, ha establecido la posible conexión con esos versos de Virgilio. Cito por mi edición de La Celestina, Barcelona 1996, 27-28.

${ }^{39}$ Para el origen y la utilización posterior del episodio que el antiguo autor pone en boca de 
un tipo de muerte que lo condene a vagar junto a las almas de los amantes babilonios. En el Hades virgiliano, como hemos visto, los suicidas (y Píramo y Tisbe lo son) ocupan los «lugentes campi», que es donde Rojas también parece ubicar a los protagonistas de su obra después de sus muertes, al hacer que Melibea se quite la vida (no a la manera de Tisbe sino de Hero) y que Calisto muera inesperadamente sin confesión.

Rojas había podido tomar esta alusión a los amantes babilonios de otra de la Fiammetta (8) que Boccaccio pone en boca de su protagonista para plantear su condena por quitarse la vida y la posibilidad de la pervivencia del amor después de la muerte:

Considerate adunque costoro, mi viene la pietà dello sfortunato $\mathrm{Pi}$ ramo e della sua Tisbe [...] ed essendo per congiugnere i loro disii, perdere se medesimi [...] Oh, felici anime le loro, se cosí nell'altro mondo s'ama come in questo! Niuna pena di quello si portar adeguare al dilecto della loro eterna compagnia (8). ${ }^{40}$

Boccaccio está pensando en los «lugentes campi» que están situados después de la muerte y en los que sus moradores sienten el amor y el deseo como lo sentían en vida. Al suponer en ese lugar a los dos amantes con un mutuo deseo muy superior a las penas y castigos que puedan recibir en él no está haciendo sino recordar a Francesca al lado de Paolo con un amor placentero que no les abandona cuando lo comparten para siempre en el segundo círculo del infierno de Dante.

Juan del Encina, en el primero de sus triunfos de amor (el narrativo y no pastoril) que ya publica en su primer Cancionero (Salamanca 1496), se presenta a sí mismo, tras haber visitado la casa de la Ventura, recorriendo junto a Deseo una sierra en la que oye procedente de un bosque una "gran llanto". Siguiendo el sonido de esos lamentos llega a un "bosque de arrayanes" (después lo llama "triste boscaje"), que traduce bastante literalmente los "mirthae... silva" de Virgilio, cuyo libro 6 de la Eneida cita explícitamente con esos datos del autor y del libro de la obra:

En un bosque de arrayanes

Andaban siempre penando

Muchas damas y galanes,

Con muy tristes ademanes

De sí mesmos blasfemando.

Calisto, véase B. Morros, "La difusión de un diagnóstico de amor desde la Antigüedad a la época moderna”, Boletín de la Real Academia de la Lengua Española 79, 1999, 93-150.

${ }^{40}$ Manejo la edición de M. P. Mussini Sacchi, Elegia di madonna Fiammetta, Milán 1987, 222 . 
De sí mesmas blasfemaban

Y del amor que tuvieron,

Que penaron y murieron

Solamente porque amaban;

Recibí muy gran afruenta

Cuando vi todo aquesto;

Pareciome tal tormenta

Cual el Virgilio recuenta

En la Eneyda, libro sesto. ${ }^{41}$

En ese bosque el protagonista, que incluso se llega a desmayar (imitando en esa actitud a Dante en el círculo de los lujuriosos al oír hablar a Francesca y llorar a Paolo), contempla a muchos hombres y mujeres, todos con la peculiaridad de haber sido amantes desdichados:

Vi muchas mugeres y hombres

En este triste boscage;

Dellos conocí en el trage,

Dellos oyendo sus nombres.

Todos estos ya eran muertos,

En amores desdichados;

Hacían mil desconciertos,

Andaban todos cubiertos

De tormentos y cuidados. ${ }^{42}$

Encina tampoco ha sabido abstenerse de introducir en algún momento las "curae» virgilianas cuando describe a los pobladores de semejante bosque llenos de "cuidados" (los arrayanes también son árboles dedicados a Venus).

En el único soneto in morte que se ha conservado (Barcelona 1543) Garcilaso podía haber imaginado también a Elisa en los «lugentes campi» recibiendo en la muerte las lágrimas de amor que él mismo ha derramado en vida ante su sepultura. Si llegamos a sospechar que la difunta puede estar sufriendo en esos campos es porque el toledano precisa con cierta ironía que a ella esas lágrimas no le van a servir de nada en el lugar en el que se halla:

Las lágrimas, que en esta sepultura

Se vierten hoy en día y se vertieron,

Recibe, aunque sin fruto allá te sean. ${ }^{43}$

${ }^{41}$ A. M. Rambaldo, Juan del Encina, Obras completas, Madrid 1978, II, 97-8.

${ }^{42}$ A. M. Rambaldo, Juan del Encina, Obras completas, 99.

${ }^{43}$ B. Morros, Garcilaso de la Vega, Obra poética y textos en prosa, Barcelona1995, 47. 
Si no es en los «lugentes campi» en qué otros lugares puede suponer Garcilaso a su amada muerta: posiblemente también en el infierno cristiano, como hemos visto que Petrarca se imaginaba a sí mismo tras un suicidio que nunca llegó a poner en práctica. El toledano, además, en el segundo terceto, prevé después de su muerte la contemplación de la difunta Elisa: semejante presentimiento solo se podría cumplir si el amante y la amada comparten el mismo lugar en el más allá. El único inconveniente para aceptar esta hipótesis es el desdén con que Garcilaso se representa a Elisa incluso muerta: si la piensa sin ningún tipo de sentimiento de amor es difícil que la dama portuguesa pueda ocupar unos campos a los que sólo van las almas de quienes han amado en vida de manera muy especial. Pero Garcilaso posiblemente la ha situado en esos lugares porque ha querido someterla a una especie de castigo por la dureza con que siempre la dama lo ha tratado (y también podría recordarla enamorada de su marido Antonio de Fonseca). Si el toledano está convencido de que las lágrimas que le ofrece a la difunta no le servirán a ella para obtener ningún tipo de beneficio en el sitio en que se la ha imaginado es porque no ha olvidado el verso con que el espectro de Cintia le revela a su amante Propercio la utilidad de las lágrimas que no deja de derramar después de su muerte en el lugar del que, como hemos visto, no da muchos detalles pero que hemos identificado con los «lugentes campi»:

Sic mortis lacrimis vitae sanamus amores

'Así sanamos los amores de la vida con las lágrimas de la muerte'

Sin duda el toledano debe de estar pensando en el llanto que vierten las almas que pueblan los campos en cuestión como una especie de purificación o purgatorio que pueden permitirles a todas sin excepción alcanzar otros lugares en el otro mundo (el cielo alto de Beatriz o el tercer cielo de Laura). Es muy probable que el fruto al que se refiere nuestro poeta tenga que ver con el abandono de unos lugares en los que sitúa a su amada por el desdén que siempre le ha inspirado: si le acaba ofreciendo sus lágrimas es porque la supone sin las que debería estar derramando en la muerte (por eso con lágrimas ajenas la difunta no puede restañar las heridas del pasado). El poeta espera la llegada de la muerte para volver a ver a Elisa porque no prevé para su alma otros lugares en el más allá que los mismos que está ocupando su amada desde el instante en que dejó el mundo de los vivos. De ese modo le está anunciando, aunque sea indirectamente, que la seguirá amando tras su muerte y que las suyas no serán por tanto "cenizas desdeñosas".

En una muy original versión del tópico del «Collige, virgo, rosas», el poeta francés Pierre Ronsard, en uno de sus sonetos más conocidos, que forman parte de los Sonnets pour Hélène, incluidos en Les Oeuvres (París 1578), se representa a la amada Hélène de Surgères ya muy vieja cantando los versos 
que él le había escrito cuando todavía era joven; en ese futuro imaginado el poeta ya ha muerto y se halla en un lugar en el que tal vez conserva el amor que había sentido en vida:

Je serai sous la terre, et fantôme san os

Par les ombres myrteux je prendai mon repos $(9-10)^{44}$.

Ronsard llama "ombres myrteux» al lugar que Virgilio había identificado como «myrtea circum silva tegit» y Marino como «selva umbrosa de... mirti»: el lugar en que el poeta latino había situado las sombras de los que no han podido desprenderse de sus preocupaciones amorosas. Ronsard no parece dar, por tanto, al sustantivo «repos» su sentido más literal ('descanso') sino otro más general, posiblemente sinónimo de 'morada' (o es posible que identifique "les ombres myrteux" como de "repos" porque recuerda que bajo ellas acaba deteniéndose Dido tras recorrer como una posesa los «lugentes campi»).

Tansillo, como he dicho un poco más arriba, no parece haberse inspirado en una dama de carne y hueso: sus editores al menos no han logrado identificarla. No hay duda, por tanto, de que la dama en cuestión es la propia Dido. Por si la hubiera, Tansillo la disipa al recordar que la misteriosa dama (que ya no lo es) murió cuando lo hizo la primera vez como consecuencia del hierro (esto es, la espada): "qual di ferro allora» ('cual de hierro entonces'). Nuestro poeta se ha limitado a traducir parte del verso en que Virgilio explica el tipo de suicidio de la reina de Cartago: «ferroque extremam secutam» ('y ejecutada la muerte con la espada').

Precisamente en el soneto que sitúa a continuación del que estamos analizando, el propio Tansillo describe el suicidio también con espada de la casta Lucrecia, cuyo nombre en esta ocasión se encarga de reproducir:

Poiché col ferro di su man trafisse

Lucrezia il casto petto $[\ldots]^{45}$

La inclusión del soneto sobre el suicidio de Lucrecia inmediatamente después del nuestro no hace sino confirmar (por si había alguna duda) que la "donna" muerta también "del ferro" es la reina de Cartago.

El poeta de Venosa en su soneto se limita a reescribir básicamente el conocido pasaje en que Eneas desciende al Hades y se encuentra en uno de los lugares (el campo de los que lloran y la selva de los mirtos) a la mujer que se había suicidado con su propia espada. Es un lugar en el que moran las almas de las damas que habiendo sufrido en vida por amor seguían conservando en

${ }^{44}$ Cito por la edición de F. Joukovsky, Les amours, París 1974, 336; en nota el editor identifica «les ombres myrteux» con «Le bois de myrtes, aux Enfers, séjour des amants» (416).

${ }^{45}$ E. Pèrcopo, Luigi Tansillo, Il Canzoniere edito ed inedito, II, 207. 
la muerte esas mismas preocupaciones. Cuando se plantea la caracterización de la dama de su soneto el poeta napolitano insiste en presentarla muy enamorada y celosa del bien que en ningún momento identifica con su marido. Virgilio, en cambio, describe, como hemos visto, a Dido vagando por un bosque con la herida aún fresca por la espada con la que se había dado muerte; pero fría e indiferente a las lágrimas de un conmovido Eneas. No la muestra celosa porque su amante troyano aún no ha conocido a Lavinia (pero ya se la menciona en el mismo Hades y aparecerá en el libro siguiente).

En el segundo cuarteto, Tansillo se refiere a los dos sucesos en la vida de Dido en torno a los cuales establece la correspondencia entre el dolor que la reina padeció en vida y el que padece después de la muerte en el campo del llanto:

Ben proverá quell'alma duol profundo,

Ch'amò piú voi che la sua spoglia viva,

Quando saprà che'l ben, di che l'ha priva

Avverso, or dona altrui fato secondo

En el verso segundo de este cuarteto, el poeta italiano introduce un pronombre ("voi") que parece usar como apóstrofe a Eneas antes que a un hipotético destinatario del soneto. No tiene demasiado sentido pensar que nuestro poeta está confesando que ama más a su señora que a Dido con vida, porque el antecedente (y por tanto sujeto de "amò") del relativo "ch" es obligatoriamente el alma de Dido. En ese caso "voi” sólo puede referirse a Eneas, a quien la reina de Cartago habría amado más que a sí misma cuando estaba viva: su hondo dolor en el más allá sólo puede entenderse y justificarse por haber amado desmesuradamente en vida (se la ha situado precisamente en un lugar en que solo pueden estar quienes cumplen esa condición).

Si Tansillo se decide a mencionar en los versos siguientes los dos hados que han determinado la desgracia de su protagonista (Dido) es porque ha querido desvincularla de otra que no la considera influida por ellos: recuerda que un hado adverso le ha privado de su bien (la persona amada) y que otro favorable ("secondo") se lo ha entregado a una dama distinta. En el segundo hado alude claramente al nuevo amor que Eneas siente por Lavinia, pero en el primero no se refiere al suicidio de Dido sino a su causa, el abandono de que ha sido objeto por el troyano. Si ha llegado a semejante conclusión es porque conoce un verso de otro libro de la Eneida en que Virgilio interpreta el suicidio de la reina de Cartago como un suceso no determinado por el hado:

Nam quia nec fato merita nec morte peribat (Aen. 4.696)

'Porque no había perecido ni por el hado ni por muerte merecida' 
En los dos primeros sucesos (el primer y segundo hado del soneto) han participado los dioses (fundamentalmente Júpiter pero también Venus y Juno) mientras que en el otro no han intervenido para nada.

Para ponderar el dolor que había sentido en vida Dido (y que también sigue sintiendo en la muerte), Tansillo podría estar recordando el momento en que la reina de Cartago está poniendo fin a su vida clavándose primero la espada que se había dejado Eneas y arrojándose después a la pira encendida con las ropas de su amante. Es el momento en que la diosa Juno siente compasión por la moribunda y envía a Iris para que libere su alma arrancándole un mechón de su rubio cabello para entregárselo a Proserpina:

Tum Iuno omnipotens longum miserata dolorem

Difficilisque obitus Irim demisit Olympo

Quae luctantem animam nexosque resolveret artus (Aen. 4.693-5)

'Entonces la omnipotente Juno, compadecida del largo dolor y del fin arduo, [mandó] a Iris que descendiera del Olimpo a liberar el alma [de Dido] que luchaba [por desasirse] de los lazos de su cuerpo'

Si en su soneto se refiere a la muerte de Dido como producida por el dolor es que está pensando precisamente en el «longum... dolorem» que conmueve a Juno, dispuesta a no prolongárselo; y si opta por la descripción tópica de la muerte (el alma liberada del cuerpo) al ofrecer la de Dido también podría ser por haberla leído en ese pasaje del poema latino.

Si Tansillo plantea en el último terceto el regreso de la reina de Cartago a la vida para morir del mismo dolor que la primera vez es porque también debe tener presente la elegía en que Propercio narra el viaje de Protesilao desde unos campos similares, pero no idénticos, a los «lugentes» al hogar conyugal para gozar por unas horas de su esposa. Es a partir de esta historia como se le ocurre al poeta italiano la posibilidad de devolver a Dido al mundo de los vivos para experimentar el antiguo dolor. Da la impresión de no haber reconocido en la Dido que Virgilio presenta en los «lugentes campi» con el mismo dolor que le había atribuido viva en Cartago. Para el tema de la doble muerte de Dido, Tansillo recuerda sin duda la que padece Eurídice cuando Ovidio la subraya al perder Orfeo a su esposa por segunda vez : "Iamque iterum moriens... gemina nuce coniugis" (met. 10.60 y 64), ['y al morir ya de nuevo... con la doble muerte de su esposa'].

Tras leer con cierta atención el soneto y ponerlo en relación con el epígrafe que lo encabeza puede apreciarse la evidente incongruencia entre el uno y el otro. Tansillo sin duda narra el dolor que siente Dido en el Hades por estar celosa de Lavinia; el autor del epígrafe entiende que el alma a la que alude el texto debe de ser la de una dama casada que estaba celosa de la que el hado 
favorable había dado a su marido. Tansillo no da nombre al personaje de su poema porque siempre se refiere a él como alma que desciende al mundo de los muertos para quedarse en el lugar reservado a quienes habían sufrido mucho por amor y experimentaban aún su angustia.

El soneto de Tansillo aparece copiado en dos de los muchos manuscritos que han transmitido su obra poética: $C$ y $N$. El primero de los dos manuscritos, conservado en la universidad Federico II de Nápoles, es el que ha recogido más poemas del poeta de Venosa (366) y el que ofrece más garantías por presentarse como una copia de un autógrafo de Tansillo: "Rime di LT copiate dall'originale dell' autor di sua propria mano". El segundo manuscrito, preservado en la Biblioteca Nacional de Nápoles, fue copiado a principios del siglo XVII y reproduce un texto menos corregido (y es por lo tanto menos fiable $)^{46}$. Por lo que respecta al soneto objeto de este trabajo, $N$ trae lecturas que atentan contra el cómputo silábico y la rima del poema. Es el caso, por ejemplo, de los versos 12-13:

Forse tornar nel corpo onde fo

Oggi vor[r]ia che, qual di ferro allora,

Morir di duol potesse un'altra volta.

El copista de $N$ parece no haber entendido esos versos tal como los leía en su original y propone a cambio otros que considera que encajan mejor en el sentido global del poema sin percatarse de que con su modificación el verso 13 no rimaba con el 14. El problema de la dama (es decir, Dido) a la que Tansillo dedica su soneto es que se halla en una zona del Hades en que experimenta las mismas sensaciones que en vida, y es en esa situación en la que desea el mismo final que cuando decidió suicidarse. En el manuscrito $C$, la dama cuenta que en ese momento en que siente celos en el campo del llanto y en la selva de mirtos es cuando se duele de haber perdido la vida ('acaso se dolerá de que hoy esté [el alma] liberada del cuerpo'), porque cree que puede morir por segunda vez del mismo dolor que cuando en la primera se quitó la vida con la espada ("qual di ferro allora»).

En $N$, el alma de Dido expresa el deseo de volver a ocupar el mismo cuerpo que tuvo en la vida que ha dejado atrás para de ese modo morir por segunda vez a causa del dolor que la mató la primera. No piensa someterse a las aguas del río Leteo para purificarse en su valle y volver al cabo de miles de años a un nuevo cuerpo en la tierra. Porque de hacerlo adoptaría un nuevo cuerpo (no el mismo de su vida anterior) y se olvidaría del amor (y también de dolor) que sintió hacia ese hombre (Eneas) por el que se quitó la vida. En

${ }^{46}$ Para una descripción de esos manuscritos, véase E. Pèrcopo, Luigi Tansillo, Il Canzoniere edito ed inedito, I, 67, y también E. Milburn, Luigi Tansillo and Lyric Poetry in Sixteenth-Century Naples, Leeds: Modern Humanities Research Association, 2003, 3-11. 
la Eneida, Anquises se lo explica a su hijo en unos pocos pero extraordinarios versos:

Animae, quibus altera fato corpora debentur, Lethaei ad fluminis undam securos latices et longa oblivia potant (Aen. 6.713-5).

‘las almas, a las que el hado debe otro cuerpo, beben en las ondas del río Leteo aguas que otorgan la paz, la tranquilidad, y un largo olvido.'

En la versión de $N$, la dama en cuestión pretende regresar a la vida desde el dolor, el de quienes permanecen en el campo del llanto y en la selva de los mirtos, pero semejante retorno no era factible emprenderlo con el cuerpo sino con la sombra. Es como lo plantea Propercio cuando narra el regreso de Protesilao a la vida para gozar durante tres horas de su esposa. En cierto modo la lectura de $N$ no carece de sentido al proponer una suerte de milagro que sólo puede resultar explicable por el amor y dolor desmesurados; pero plantea tales inconvenientes formales, que es forzoso entenderla como conjetura de su copista y no una versión anterior de su autor.

Por su parte, Berardino Rota compuso todo un cancionero in morte consagrado a su esposa Porzia Capece y unas cuantas églogas piscatorias que influyeron en las barquillas que Lope de Vega intercaló en La Dorotea (Madrid 1632). Se le atribuye un soneto en que se refiere no sólo a la muerte de su amada o esposa (Porzia Capece, si es de Rota) sino también a la de Irene de Spilimbergo (ocurridas las dos en 1559), pintora que estuvo trabajando los últimos años de su vida en Venecia con Tiziano. El soneto no aparece publicado junto a los más de cuatrocientos (entre italiano y latín) que constituyen el volumen de poesía compuesto y reunido por Dionigi Atanagi en homenaje de la pintora con motivo de su muerte: Rime di diversi nobillissimi ed eccellentissimi autori in morte della signora Irene delle signore di Spilimbergo (Venecia 1561) ${ }^{47}$.

Escribiera quien escribiera el soneto en cuestión su autor no debió de empezarlo antes de finales de 1559 o principios de 1560, porque Irene falleció

${ }^{47}$ En el volumen se incluyen 279 poemas en italiano y 142 en latín de autores tan importantes en la época como Bernardo y Torquato Tasso, Lodovico Dolce, Girolamo Muzio, Benedetto Varchi, Lodovico Domenichi, etc. Véase al respecto Anne Jacobson Schulte, "Irene di Spilimbergo: The Image of a Creative Woman in Late Renaissance", RenQ 44, 1991, 42-61; y Antonio Corsaro, "Dionigi Atanagi e la silloge per Irene di Spilimbergo. Intorno alla formazione del giovane Tasso", Italica, 1998, 41-61, con abundante bibliografía sobre el tema en 55 (n.2) y 57 (n.14). 
en diciembre del primero de esos dos años. El poeta, que lo dirige a dos amigos -también poetas-- de la difunta, confiesa no tener las fuerzas suficientes para expresar el vacío que ha dejado la bella Irene porque debe de emplearlas, al haberse ido al cielo la que considera «vita mia» (Porzia Capece, si es de Rota), en recorrer el "campo di pianto». Al haberse quedado sin vida, por tenerla ya en el cielo, se ha quedado también sin voz ni estilo para dar rienda suelta al dolor:

S'io fossi ch'io era, o s'io [non] vivessi

Senza la vita mia ch'al ciel sen gio,

O se campo di pianto acerbo e rio

Da spatiar dí e notte io non havessi

Direi, se dirne almen parte potessi,

Quanto di te lasciasti a noi desio,

Irene bella, ch'anchor presso a Dio

Dipingi e canti i tuoi gran pregi stessi.

Ma poiché dietro il mio bel lume amico

La voce con lo stil tosto è sparita,

Né altro fuor che morte in me si vede,

Ogni, che fate il secol nostro antico,

Mi volgo a voi qual huom muto che chiede

Con gli occhi e con la man pietosa aita $(73) . .^{48}$

No está demasiado claro si este "campo di pianto» (nótese el singular) es el lugar del infierno al que se refieren tanto Virgilio y Tansillo y en el que sitúan a una todavía convaleciente Dido. Es posible que nuestro poeta para ponderar su amor y el de su amada (posiblemente su esposa) haya pensado en ese lugar del Hades como el lugar al que bajaría él desafiando al barquero Caronte y en el que permanecería ella por conservar tras la muerte sus sentimientos hacia su marido (Virgilio también permite el amor conyugal en los campos del llanto y la selva de los mirtos). Si los versos pueden leerse como acabo de proponer, y no lo impide la alusión a la noche y el día, como hemos tenido ocasión de comprobar al estudiar el soneto de Giovanni Della Casa, está claro que el poeta asume para sí el papel de Eneas que en los «lugentes campi» no puede evitar las lágrimas por una reina a la que ha amado profundamente pero a cuyo amor ha debido renunciar por obedecer a un destino (el de los dioses) que le había reservado en el Lacio otra mujer. Por esos campos también hemos visto vagar a la fiel esposa de Protesilao, Laodamía, que se había suicidado para reunirse con su marido en algún lugar del mundo de los muertos. Virgilio, sin embargo, se la imagina sola, porque debe haber previsto para

${ }^{48}$ Este soneto está incluido en Bernardino Rota, Rime rifiutate, reproducidas en Biblioteca Italiana, 2004. 
el tesalio los campos más distantes en los que sitúa a los varones más famosos en guerra. Son los mismos campos en que lo describe Propercio regresando a la vida para gozar por unas horas del cuerpo de su esposa.

Rota (o quien haya escrito el soneto) se representa, en cambio, a Irene junto a Dios pintando y cantando sus propias virtudes ajena a los dolores de las almas que vagan por los campos del llanto. No es ocioso recordar que Virgilio sitúa al músico Orfeo, mucho más allá del Aqueronte y del Leteo, cantando en los Campos Elíseos. Establece, pues, una clara relación entre las actividades de la pintora (también cantaba) y el esposo de Eurídice.

Luigi Tansillo también dedicó dos sonetos a lamentar la muerte de Irene incluidos en el volumen de Rime in morte di Irene. Solo en uno vuelve a tener bastante presente la Eneida de Virgilio. Es un soneto en que se imagina a la pintora regresando del cielo vestida de mil colores, después de la tormenta, para con su bello nombre inundar de paz y alegría la tierra. Pensando en ese final para el poema ha elegido a Iris como punto de referencia para establecer afinidades y diferencias con la diosa. En esos últimos versos recuerda la etimología del nombre de la difunta (Irene, eỉ nifica 'paz') y también la de Iris, con la misma raíz que Irene ( $\varepsilon 1$ ' $\rho \omega$, 'anuncio, mensaje'); y juega con una clara paronomasia entre los dos nombres ("Irene, piú d'Iri...”):

Non può gran tempo ir chiusa d'uman velo

Alma, che troppo adorna quaggiú vene;

Onde preme sí tosto, o bella Irene,

I fior del tuo bel viso estremo gelo.

Or sei là, 've già viva arse il suo zelo;

E cangi con l'eterno il frágil bene:

Già le nubi e le piogge rasserene,

Nova ministra de Giunon nel cielo.

Verrai di mille bei color vestita,

Quando piú freme il mar e l'aria tona,

Con celeste arco a rallegrar la terra,

Tanto, Irene, piú d'Iri qui gradita,

Quanto sarai, qual il bel nome sona,

tu messaggio de pace, ella di guerra. ${ }^{49}$

En el primer cuarteto, asegura que un alma con tantas virtudes como la de la pintora no podía vivir demasiado tiempo encerrada en un cuerpo; y describe por tanto los estragos que la fría muerte («estremo gelo») ha provocado en la flor del bello rostro de Irene. En estos versos iniciales, como también en los finales, deja oír diferentes versos in morte de Petrarca. Para unos y otros

${ }^{49}$ E. Pèrcopo, Luigi Tansillo, Il Canzoniere edito ed inedit, 198. 
ha podido tener en mente varios de la canción 268 del aretino: «Oimé, terra è fatto il suo bel viso» $\mathrm{y}$ "'l suo chiaro nome,/ que sona nel mio cor sì dolcemente» (vv. 34 y 49-50) ${ }^{50} ; \mathrm{y}$, especialmente para los dos últimos, ha pretendido el mismo efecto que con los suyos Alessandro Sforza en su Canzoniere:

Pur quel bel nome ma a mi si fuge,

Che pace sona Amor... (12-3) .

En el segundo cuarteto, menciona a Iris como fenómeno atmosférico pero también como diosa del Olimpo en la función de criada y camarera de Juno. Es el oficio en el que piensa cuando para referirse a la primera la llama "ministra", sustantivo al que da el sentido etimológico de "criada, sirvienta, esclava'. El dato sobre el oficio de Iris pudo haberlo tomado del Baño de Delos (4.232-9) de Calímaco y de los Idilios (17.134) de Teócrito52.

Para los efectos que la bella Irene, al regresar a la tierra, produce en sus campos («Già le nubi e le piogge rasserene» $\mathrm{y}$ "Con celeste arco a rallegrar la terra»), Tansillo podía estar recordando, dentro del tópico de la amada que con su vista o presencia ejerce una influencia benefactora sobre la naturaleza, unos versos de la Favola di Leandro e d'Ero en los que Bernardo Tasso se la atribuye a la diosa Venus:

Santa madre d'Amor, primo e maggiore

Dilecto degli Dei, che col tuo lume

Rendi l'aere seren, lieta la terra $(23-5)^{53}$.

También el poeta italiano habrá tenido en cuenta, como veremos en seguida, la descripción que hace Virgilio sobre los efectos que produce Iris en el cielo precisamente cuando narra la intervención de la diosa como mensajera de Juno para desencadenar la guerra entre latinos y troyanos. El poeta latino hace notar la claridad que provoca la criada de Juno al descorrer el velo celeste que en pleno día esconde las estrellas e impide que su luz llegue iluminar más a la tierra (Aen. 9.14-21).

En los tercetos, Tansillo desarrolla esas dos imágenes de la diosa: Irene desciende del cielo como arco que con sus colores (porque era pintora) alegra el mundo y también como portadora de un mensaje de paz, frente a Iris, que lo es de otro de guerra. Para establecer esa contraposición de paz y guerra ha tenido en cuenta (aparte el sentido que el nombre de Irene tenía en griego) la procedencia de la difunta y de la criada de Juno. Ha situado a la primera en el

${ }^{50}$ M. Santagata, Francesco Petrarca. Canzoniere, 1067.

${ }^{51}$ El Canzoniere de Alessandro Sforza puede leerse en Biblioteca Italiana, 2004.

${ }^{52}$ Para este tema, véase María Isabel Rodríguez López. "Iris, la mensajera de los dioses (Estudio iconográfico de sus representaciones en el arte griego)”, Anales de Historia del arte, 14, 2004, 7-31.

${ }^{53}$ D. Chiodo, Tasso. Rime, 390. 
cielo (seguramente en los Campos Elíseos) pensando que ese lugar es lugar en que habitualmente suele situarse la paz y la tranquilidad. Para llegar a semejante relación podía haber leído los pasajes en los que Dante la deja muy clara:

Lo creatore a quella creatura

Che solo in lui vedere ha la sua pace (Paradiso 30, vv. 101-2) ${ }^{54}$.

Y, si no, también habría tenido muy presentes unos versos en los que Petrarca introduce un contraste entre el tipo de vida que imagina para Laura en el Paraíso y la que lleva él en la tierra sin la compañía de su amada:

Di me vi doglia, et vindicavi pietate,

Non di lei, ch'è salita

A tanta pace, et m'a lassato in guerra $(268 \text {, vv. 59-61) })^{55}$.

Es posible que para establecer la vinculación de Iris con la guerra Tansillo haya pensado o bien en la genealogía de la diosa como hermana de las Harpías (a las que Virgilio sitúa en el infierno) o bien en el papel de la diosa como anunciadora de noticias funestas pero también en el de su señora Juno como provocadora de guerras. El poeta italiano sin duda ha tenido presente el pasaje, situado en el libro $\mathrm{V}$ de la Eneida, en que la esposa de Júpiter envía a su criada a incendiar las naves troyanas. Para inmiscuirse entre sus mujeres sin llamar la atención Iris se transforma en una de ellas, la anciana Béroe, y con su nuevo aspecto las incita a prender fuego en sus naves para poder quedarse donde en ese momento están (la tierra de Érice) y poner fin de ese modo a siete años recorriendo los mares:

Irim de caelo misit Saturnia Iuno

Iliacam ad classem ventosque aspirat eunti,

Multa movens necdum antiquom saturate dolorem.

Illa viam celerans per mille coloribus arcum

Nulli visa cito decurrit tramite virgo (Aen. 5.606-10).

'La saturniana Juno envía desde el cielo a Iris a la flota troyana y hace soplar los vientos para que la favorezcan, provocando muchas cosas todavía no satisfecha de su antiguo dolor. Aquella doncella, acelerando su marcha a través de su arco de mil colores, sin ser vista, desciende por un camino rápido.'

Tansillo podía estar pensando también en el principio del libro 9 en que Juno manda esta vez a Iris a prevenir a Turno para la guerra contra Eneas.

${ }^{54}$ D. Matalia, Dante. Divina Commedia, 890.

${ }^{55}$ M. Santagata, Francesco Petrarca. Canzoniere, 1067. 
Tras haber transmitido su mensaje al rey de los rútulos, Iris emprende el vuelo y en su rápido ascenso trenza sobre las nubes el arco que le da el nombre. Turno la reconoce en seguida porque nota en el ambiente una claridad y resplandor inusuales producidos por la presencia de la diosa, quien ha descorrido el velo celeste que durante el día suele ocultar las estrellas:

Irim de caelo misit Saturnia Iuno

Audacem ad Turnum [...]

Dixit et in caelum paribus se sustulit alis

Ingentemque fuga secuit sub nubibus arcum [...]

"Iri, decus caeli, quis te mihi nubibus actam

Detulit in terras? Unde haec tam clara repente

Tempestas? Medium video discedere caelum

Palantisque polo stellas (Aen. 9.2-21).

'La saturniana Juno mandó a Iris desde el cielo al audaz Turno [...] Dijo [Juno] y se alzó hacia el cielo con sus alas iguales y en su fuga dibujó sobre las nubes su arco inmenso [...]. "Iris, esplendor del cielo, ¿quién te ha hecho descender desde las nubes a la tierra en mi busca? ¿De dónde procede de repente tan clara atmósfera? Veo abrirse el centro del cielo y las estrellas andar errantes por el firmamento.'

Menos probablemente Tansillo podría aludir a otro pasaje de la Eneida en que Virgilio presenta a Juno también como la causante del enfrentamiento entre troyanos y latinos (Aen. 7.287-504). En esos versos su autor describe el descenso de la propia Juno a la tierra para sacar de las tinieblas infernales a una de las tres furias, Alecto, y enviarla al palacio de Turno con la misión de ponerlo en pie de guerra contra Eneas (Aen. 8.325). La furia se ha presentado ante el prometido de Lavinia transformada en la sacerdotisa de Juno, la anciana Cálipe, también guardiana de su templo.

Si Tansillo supone a Irene ocupando el Paraíso o los Campos Elíseos es para contraponerla a una Iris que desempeña el papel que Virgilio ha adjudicado a la desencadenadora por excelencia de las guerras: la furia Alecto que adopta el aspecto de la vieja sacerdotisa de Juno. Es por tanto verosímil que Tansillo haya podido confundir a la sacerdotisa de Juno con una de las criadas y principal mensajera de la diosa, sobre todo teniendo en cuenta que el papel de la sacerdotisa y la criada lo desempeña en la Ilíada la diosa Eris, quien "fomenta la guerra y la batalla malvadas" (Hesíodo, Los trabajos y los días, 11-24). Al principio del libro 11 de esa obra Homero narra la misión que Eris lleva a cabo por mandato de Zeus en las naves aqueas para provocar a sus ocupantes al combate contra los troyanos (1-14).

Para la descripción del descenso de Irene a la tierra nuestro poeta ha podido usar la que hace Virgilio cuando refiere el de Iris desde el Olimpo para posarse en la cabeza de Dido: 
Ergo Iris...

mille trahens varios... colores (Aen. 4.700-1).

'Pues Iris... descendiendo con mil colores diversos.'

Tansillo también habría podido tomar en consideración la que incluye Ovidio en el relato de la fábula de Céix y Alcione (pero en este caso Iris no desciende a la tierra sino que se dirige a la morada del Sueño):

induitur velamina mille colorum (met. 11.589)

'se viste sus ropas de mil colores'

Tansillo y Rota han utilizado para sus respectivos sonetos distintos pasajes de la Eneida que a veces (en el caso del primero) han llegado a recordar con cierta literalidad. En sus versos han intentado brindar dos imágenes contrapuestas de las damas cuya vida y muerte han llorado. Tansillo no ha dudado en seguir ubicando a Dido en ese oscuro lugar entre los ríos Aqueronte y Leteo asignado sólo a las almas que no han sabido o podido renunciar al amor. Tansillo y Rota tampoco han vacilado a la hora de imaginarse a Irene cerca de Dios, más allá de la muerte, del amor y del olvido, despojada ya definitivamente del tiempo. Tansillo ha pensado a Irene con la misma alegría y tranquilidad con que lo haría (a propósito de otra Irene mucho más nuestra y cercana) muchos siglos después el poeta ovetense Ángel González, quien también presenta a la bella Irene (con una imagen digna de Petrarca) inundando de paz y calma cualquier aurora con sólo invocar su bello nombre y recordar su bella sonrisa:

Cuando sonríes, te pienso Irene, y la sonrisa tuya es mucho más que tu sonrisa: Amanece sin sombras la alegría del mundo. ${ }^{56}$

${ }^{56}$ Estos versos forman parte del poema "También un nombre puede modificar un cuerpo", en el que su autor -en una técnica practicada especialmente en el Barroco español- disemina al principio unas palabras claves que recoge al final: "más nácar" (2), "espuma indecisa" (5), "rubor palidece" (8), "traslúcida" (9), "llanto" (13) y "alegría" (18) son las palabras que vuelve a mencionar exactamente igual entre los versos 22 y 25 , salvo "rubor palidece” y "traslúcida”, que convierte en "palidez rosada" y "transparencia". El poema en cuestión puede leerse en Palabra sobre palabra, Barcelona 2005, 220. 